\title{
Study of the Impact of Technical Malfunctioning of Vital Vehicular Parts on Traffic Safety
}

\author{
Đorđe VRANJEŠ, Jovica VASILJEVIĆ, Goran JOVANOV, Radovan RADOVANOVIĆ, Tihomir ĐURIĆ
}

\begin{abstract}
The paper aims to present the results of study on how certain types of vehicles with malfunctioning technical parts affect traffic safety in the Republic of Serbia between 1997 and 2014. The following methods were used in the paper: statistical method, comparative method, analysis of frequency of defined traffic accident causes, Pearson linear correlation with a modelled algorithm for data processing. The technical malfunction of vehicles as a cause for accident occurrence has a share of $0,72 \%$ in the total number of accidents. The most common cause of accidents lies with malfunctioning lights or light-signalling devices on vehicles. The technical malfunction of vehicles has the highest value of $1,65 \%$ in accidents with fatalities and the biggest correlation between accidents at police district and accidents on national level is recorded with accidents in which only material damages were sustained. The research results can be used for comparison on regional level, so as for developing of the model of analysis of the causes of traffic accidents in Serbia and in the region.
\end{abstract}

Keywords: technical malfunction; traffic accidents; traffic safety; vehicles

\section{INTRODUCTION}

It has been established in the field that the vehicle as an element of traffic safety contributes around $13 \%$ to the occurrence of traffic accidents [14]. Roadworthiness of vehicles is crucial for a sustainable state of traffic safety. According to the data by European Commission, more than five persons die every day on the European Union territory in traffic accidents caused by vehicles with malfunctioning technical parts [14].

Data on technical and exploitation characteristics show that roads abound with vehicles that are technically malfunctioned and ripe for the recycling process [6]. In addition, a great number of vehicles do not meet the basic environmental criteria defined by international regulations and standards [1].

Results of numerous studies have shown that proper roadworthiness inspection contributes to the reduction in number of accidents with fatalities. In relation to this, in [7] authors have confirmed in their research that periodic technical inspection of vehicles significantly contributes to reducing the most serious consequences in traffic accidents.

In [8] is reached the conclusion that tires and brakes are the two most dominant components whose mechanical defects cause traffic accidents that lead to the rollover of a vehicle. According to the results of their study, $40 \%$ of vehicles in suburban areas and $29 \%$ of motorway vehicles have mechanical defects that may contribute to the occurrence of traffic accidents.

Vehicles of inferior roadworthiness run a much higher risk of partaking in traffic accidents than roadworthy vehicles $[9,10]$.

In study [14] a conclusion is reached that the reduction in vehicle inspection of heavy duty vehicles can lead to an increase $(5-10 \%)$ of their share in traffic accidents with fatalities. It is also concluded that an increase of $100 \%$ in vehicles inspection is closely related with a minimal reduction in the number of traffic accidents.

In the research conducted by [12] it was not found that periodic vehicle inspections have an influence on the reduction in the number of traffic accidents.
In study [3] the following conclusions are reached while conducting an analysis of the impact periodic vehicle inspections have on traffic safety in Norway:

1. Technical malfunctions of vehicles are connected with a small but statistically relevant increase in the rate of traffic accidents,

2. Periodic vehicle inspections lead to the elimination of technical malfunctions on vehicles,

3. Conducting periodic vehicle inspections does not lead to a decrease in the rate of accidents with vehicles inspected, but it does show a weak tendency of increase.

In summation of all the conclusions from the research, the rest of the paper presents the results of data analysis on traffic accidents caused principally by technical malfunction of vehicles according to the defined branchsubcategories.

The basic aim of the research was to find results that would lead to a conclusion as to what extent vehicles with technical malfunction have the biggest impact on the occurrence of traffic accidents and their consequences. In the end, the hypothesis of the research is defined in such a way that the results of the research can show which type of traffic accidents are caused by technical malfunction of vehicles with the greatest correlation at the level of police districts and at the national level, i.e. the level of the Republic of Serbia.

\section{RESEARCH METHODOLOGY}

Statistical data on traffic accidents in the Republic of Serbia from 1997 to 2014 is procured from the Unique database of relevance to traffic safety, run by Road Traffic Safety Agency of the Republic of Serbia [2].

Samples of traffic accidents related to technical malfunction of vehicles were selected from the entire database: malfunctioning or unsuitable tires, malfunctioning steering device, malfunctioning device for linking towed or trailer vehicle, malfunctioning braking device, malfunctioning lights and/or light-signaling devices and other malfunctions on a vehicle.

Data for the 1997-2014 period was analyzed for the entire region of the Republic of Serbia and the areas that territorially consist of police districts, of which there are 27. 
The frequency analysis of the defined causes of traffic accidents that are relative to the technical malfunction of vehicles was observed within the total number of traffic accidents with fatalities (TA FAT), total number of traffic accidents with injured persons (TA INJ), total number of accidents with casualties (TA CAS), total number of accidents with material damages only (TA MD) and total number of accidents that consist of traffic accidents with material damage and accidents with fatalities (TA TT).

Apart from the frequency analysis, a comparative analysis of the rate of certain kinds of accidents at the level of 27 police districts and at the level of the Republic of Serbia was conducted, by applying the algorithm model from Fig. 1 for consequences of traffic accidents that are caused by technical malfunction of vehicles, and the results of that research are shown in Tab. 3 .

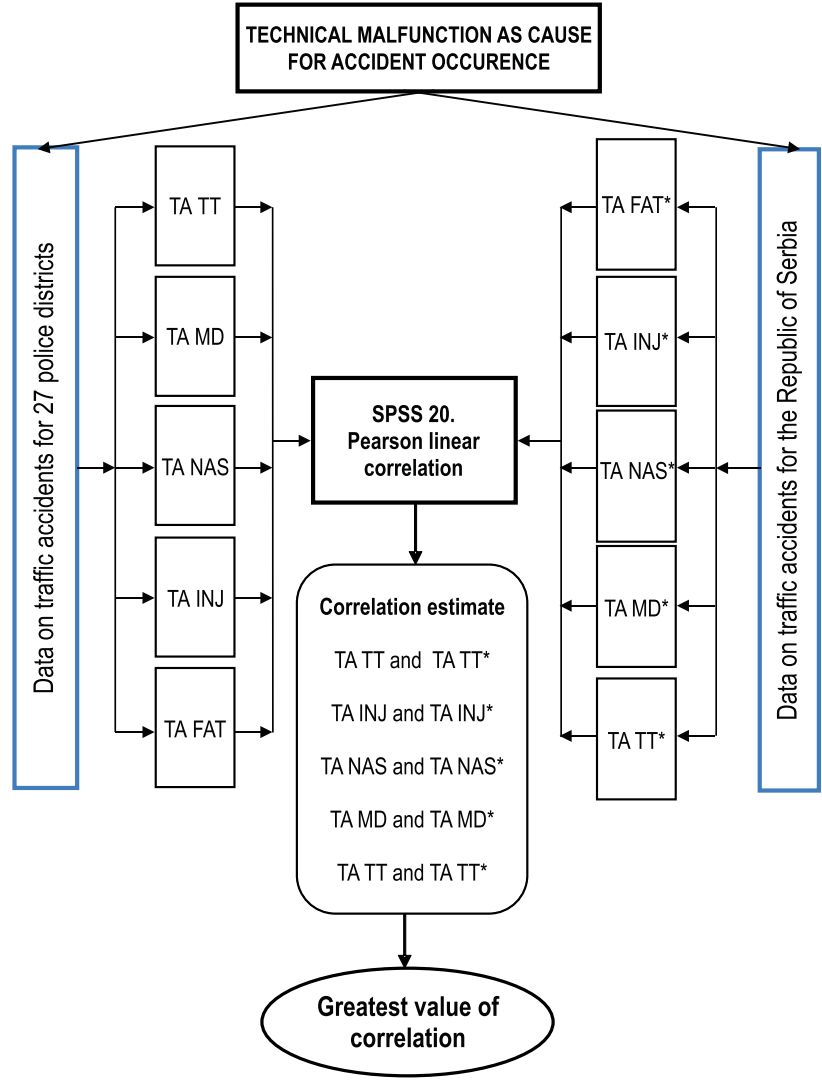

Figure 1 Algorithm of the model for analysis of the Pearson correlation value between variables at the level of police districts and at the level of the Republic of Serbia.

Data processing was carried out by using the Pearson linear correlation in SPSS 20 Statistics software tool. During data processing, a comparison was made between continuous variables that are relative to traffic accidents caused by a technical malfunction of vehicles, and the total number of accidents.

Values achieved with the Pearson linear correlation method are supposed to point out the strength and direction of the connection between variables at the level of police districts and at the level of the Republic of Serbia. Values range between -1 and 1 , and the sign marks the direction of the connection between analyzed variables.

All selected variables relative to the number of traffic accidents are continuous, and the result value of the variable $(\mathrm{P})$ shows the strength of connection.
In this segment the principal aim was to establish which variable describing the number of accidents caused by technical malfunctions impacts the occurrence of traffic by technical malfunctions of vehicles has the greatest correlation value and statistical significance of the achieved result in relation to the level of police districts and the national level.

\section{RESULTS OF THE RESEARCH}

On the basis of the analysis carried out for the total number of accidents caused by technical malfunction of vehicles (TAtmv) in the total number of traffic accidents in Fig. 2, results are shown as percentage rates for certain types of accidents.

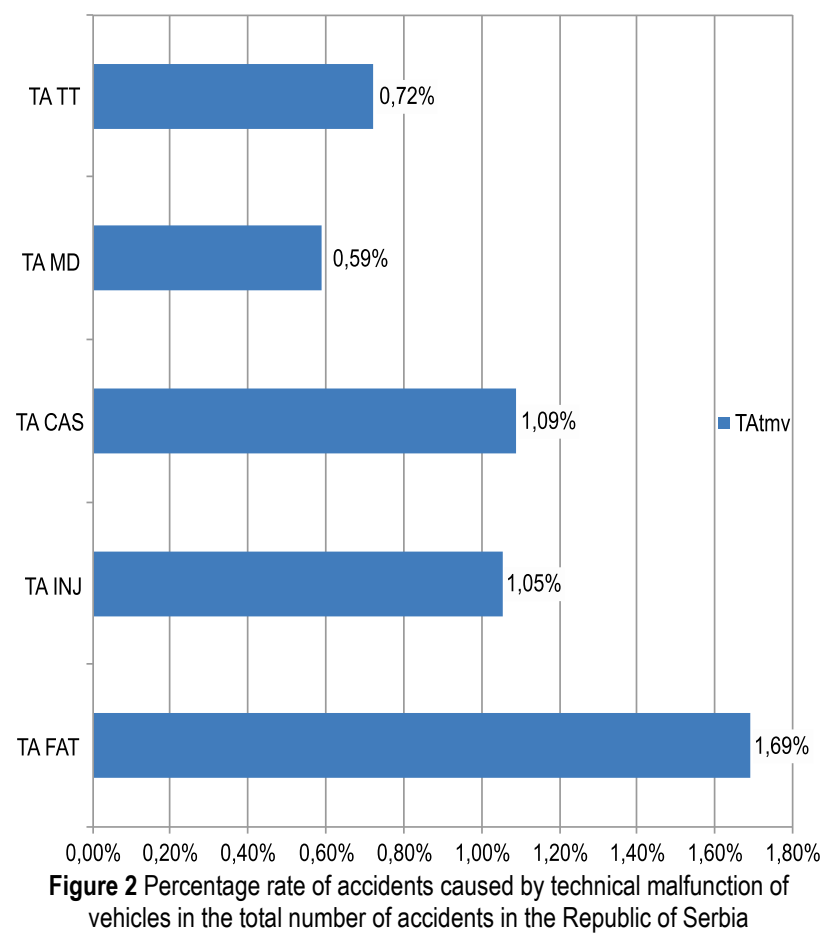

Compared to the total number of traffic accidents in the Republic of Serbia in the 1997-2014 period TAtmv has an incidence of mere $0,72 \%$.

The greatest value of TAtmv was observed in traffic accidents with fatalities and it is $1.69 \%$. The smallest value of $0.59 \%$ was observed in traffic accidents with material damages only.

In traffic accidents with injured persons a value of $1.05 \%$ was recorded, and finally the value of $1.09 \%$ was recorded in accidents with fatalities.

Next, in Tab. 1, an overview of the number of traffic accidents caused by technical malfunction of vehicles is shown, according to the type of accident and the basic cause.

By analyzing the results from the frequency analysis in TA FAT, it can be concluded that almost a half of these accidents $(48,97 \%)$ are accidents caused principally by malfunctioning lights and/or light-signalling devices on a vehicle. Malfunctioning or unsuitable tires are the least prevalent cause in TA FAT, with the value of $1,38 \%$.

Accidents in TA INJ caused principally by malfunctioning lights and/or light-signalling devices on a vehicle make up $39.62 \%$. The smallest value in the total 
number of TA INJ belongs to accidents caused by a malfunctioning or unsuitable tire $(1,57 \%)$.

When TA CAS is taken into account, which represents the sum of TA FAT and TA INJ, the prevalence of causes is the same as in the previous two types of accidents, and $40.48 \%$ accounts for accidents principally caused by a malfunctioning or unsuitable tire.

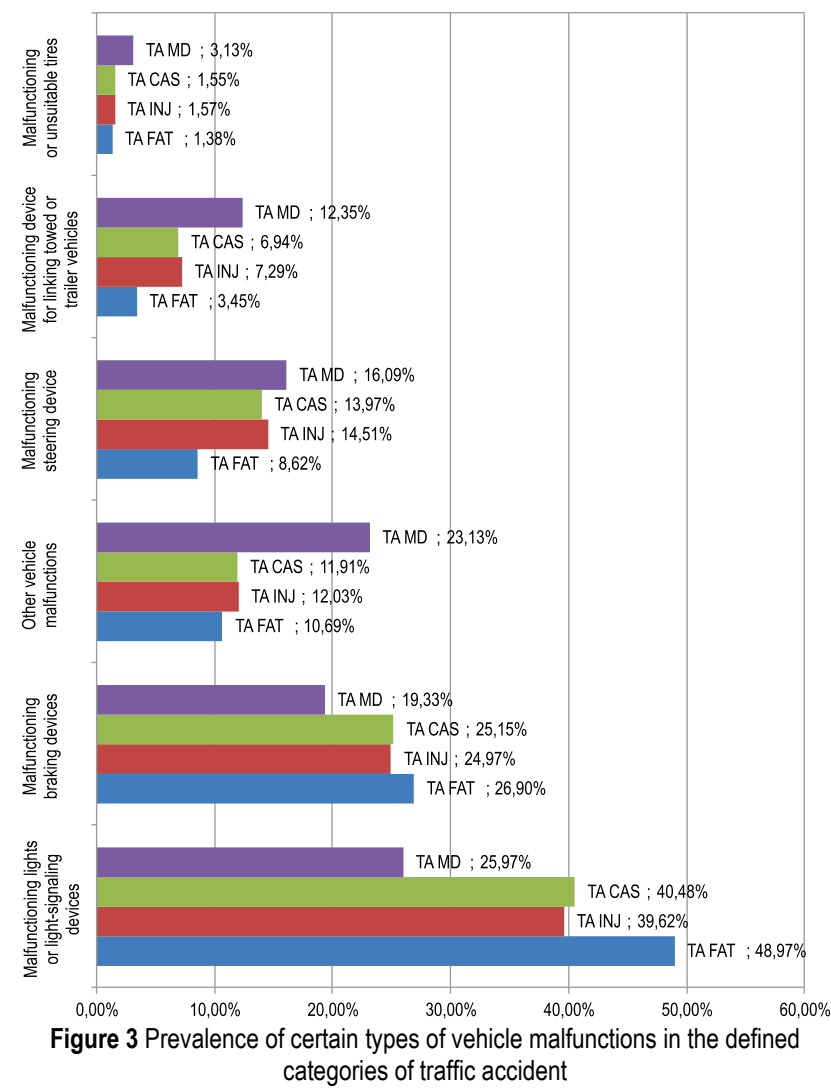

In TA MD, accidents caused by malfunctioning lights and or light-signalling devices on a vehicle make up $25,97 \%$, and accidents caused principally by a malfunctioning or unsuitable tire make up $3,13 \%$ of the total figure.

Summed up results from Tab. 1 are shown in Fig. 3, so as to allow for a mutual comparison between key causes of accidents from the segment of technical malfunction and the type of consequences it produced.

Malfunctioning or unsuitable tires were the least prevalent cause in all types of traffic accidents. The greatest value for this cause was found in TA MD, with the amount of $3,13 \%$.

Malfunctioning device for linking towed or trailer vehicles was most prevalent as a cause in TA MD, with the amount of $12,35 \%$.

Malfunctioning vehicle steering device recorded the greatest value of $16,09 \%$ in TA MD, and the smallest of $8.62 \%$ in TA FAT.

Malfunctioning braking devices on vehicles have the greatest value of $26,90 \%$ in TA FAT, and the smallest value of $19,33 \%$ in TA MD.

Malfunctioning lights and/or light-signalling devices as a cause for accident occurrence show the greatest value of $48,97 \%$ in TA FAT, and the smallest value of $25,97 \%$ in TA MD.

The last of the defined categories for causes of accidents is other malfunctions on vehicles. This category encompasses all other causes that cannot be assigned to any of the previously listed categories of vehicle malfunctioning. Other malfunctions as a cause are most prevalent in TA MD, with $23,13 \%$, and least prevalent in TA FAT, with the amount of $10,69 \%$.

Table 1 Statistical data on traffic accidents caused by technical malfunction on vehicles and the total number of accidents in the Republic of Serbia

\begin{tabular}{|c|c|c|c|c|c|c|c|c|c|}
\hline TA CAUSE & TA FAT & $\%$ & TA INJ & $\%$ & TA CAS & $\%$ & TA MD & $\%$ & TA TT \\
\hline $\begin{array}{l}\text { Malfunctioning lights or light- } \\
\text { signaling devices }\end{array}$ & 142 & $48,97 \%$ & 1136 & $39,62 \%$ & 1278 & $40,48 \%$ & 1228 & $25,97 \%$ & 2506 \\
\hline Malfunctioning braking devices & 78 & $26,90 \%$ & 716 & $24,97 \%$ & 794 & $25,15 \%$ & 914 & $19,33 \%$ & 1708 \\
\hline Other vehicle malfunctions & 31 & $10,69 \%$ & 345 & $12,03 \%$ & 376 & $11,91 \%$ & 1094 & $23,13 \%$ & 1470 \\
\hline Malfunctioning steering device & 25 & $8,62 \%$ & 416 & $14,51 \%$ & 441 & $13,97 \%$ & 761 & $16,09 \%$ & 1202 \\
\hline $\begin{array}{l}\text { Malfunctioning device for linking } \\
\text { towed or trailer vehicles }\end{array}$ & 10 & $3,45 \%$ & 209 & $7,29 \%$ & 219 & $6,94 \%$ & 584 & $12,35 \%$ & 803 \\
\hline Malfunctioning or unsuitable tires & 4 & $1,38 \%$ & 45 & $1,57 \%$ & 49 & $1,55 \%$ & 148 & $3,13 \%$ & 197 \\
\hline Total TA tmv* & 290 & & 2867 & & 3157 & & 4729 & & 7886 \\
\hline TOTAL TA** & 17144 & & 272390 & & 289534 & & 801658 & & 1091192 \\
\hline
\end{tabular}

*Sum of traffic accidents caused by technical malfunction on vehicles

**Sum total of the number of all traffic accidents in the Republic of Serbia in 1997-2014 period

When all the data on the prevalence of certain categories of technical malfunctions as causes for traffic accident is summed up, the results shown in Fig. 4 are reached. Malfunctioning or unsuitable tires record the smallest value out of total number of accidents at $N=$ $197(2 \%)$.

Out of the total number of traffic accidents in the Republic of Serbia, in the 1997-2014 period, malfunctioning lights or light-signalling devices as a type of technical malfunction on vehicles that causes the occurrence of accidents and consequences is the most prevalent one, $N=2506(32 \%)$.

In Tab. 2 we can see an overview of the total number of traffic accidents per police districts in the Republic of
Serbia and the total number of traffic accidents caused by technical malfunctions on vehicles.

All the values shown in Tab. 2 that have the symbol * next to them (e.g. TA FAT*) are relative to the total number of accidents in the Republic of Serbia, i.e. the national level.

According to the data from Tab. 2, and with the Pearson correlation method applied, an evaluation is carried out between continuous variables that are relative to the total number of accidents caused by technical malfunctions on vehicles at the level of police districts, and the total number of accidents on the territory of the Republic of Serbia. 
According to the data from Tab. 2, and with the Pearson correlation method applied, an evaluation is carried out between continuous variables that are relative to the total number of accidents caused by technical malfunctions on vehicles at the level of police districts, and the total number of accidents on the territory of the Republic of Serbia.

Table 2 Data on the total number of accidents in the Republic of Serbia and the number of accidents caused by technical malfunctions per police districts

\begin{tabular}{|c|c|c|c|c|c|c|c|c|c|c|c|}
\hline & Police district & TA FAT & $\begin{array}{c}\text { TA } \\
\text { FAT }^{*}\end{array}$ & TA INJ & TA FAT* & $\begin{array}{c}\text { TA } \\
\text { CAS }\end{array}$ & TA CAS* & TA MŠ & TA MŠ* & $\begin{array}{l}\text { TA } \\
\text { UK }\end{array}$ & TA UK* \\
\hline 1 & Belgrade & 3 & 2953 & 77 & 52699 & 80 & 55652 & 235 & 308630 & 315 & 364282 \\
\hline 2 & Bor & 4 & 321 & 79 & 4079 & 83 & 4400 & 109 & 9367 & 192 & 13767 \\
\hline 3 & Čačak & 6 & 535 & 39 & 8723 & 45 & 9258 & 108 & 20500 & 153 & 29758 \\
\hline 4 & Jagodina & 8 & 503 & 67 & 7187 & 75 & 7690 & 112 & 14332 & 187 & 22022 \\
\hline 5 & Kikinda & 11 & 370 & 83 & 5397 & 94 & 5767 & 97 & 9651 & 191 & 15418 \\
\hline 6 & Kragujevac & 10 & 690 & 142 & 12231 & 152 & 12921 & 214 & 23903 & 366 & 36824 \\
\hline 7 & Kraljevo & 5 & 538 & 32 & 7531 & 37 & 8069 & 65 & 17432 & 102 & 25501 \\
\hline 8 & Kruševac & 11 & 529 & 145 & 8209 & 156 & 8738 & 170 & 15639 & 326 & 24377 \\
\hline 9 & Leskovac & 10 & 399 & 179 & 7494 & 189 & 7893 & 131 & 8914 & 120 & 16807 \\
\hline 10 & Niš & 16 & 743 & 175 & 13441 & 191 & 14184 & 306 & 34614 & 497 & 48798 \\
\hline 11 & Novi Pazar & 13 & 248 & 106 & 3683 & 119 & 3931 & 83 & 8040 & 202 & 11971 \\
\hline 12 & Novi Sad & 19 & 1316 & 201 & 28218 & 220 & 29579 & 595 & 101025 & 815 & 130604 \\
\hline 13 & Pančevo & 27 & 856 & 189 & 12028 & 216 & 12884 & 289 & 21820 & 505 & 34704 \\
\hline 14 & Pirot & 4 & 234 & 50 & 2602 & 54 & 2836 & 47 & 4428 & 101 & 7264 \\
\hline 15 & Požarevac & 13 & 543 & 111 & 7007 & 124 & 7550 & 256 & 17286 & 380 & 24836 \\
\hline 16 & Prijepolje & 5 & 128 & 30 & 2428 & 35 & 2556 & 60 & 5684 & 95 & 8240 \\
\hline 17 & Prokuplje & 6 & 178 & 50 & 2896 & 56 & 3074 & 71 & 4784 & 127 & 7858 \\
\hline 18 & Šabac & 14 & 892 & 92 & 11226 & 106 & 12118 & 218 & 23709 & 324 & 35827 \\
\hline 19 & Smederevo & 8 & 598 & 113 & 8685 & 121 & 9283 & 172 & 17632 & 293 & 26915 \\
\hline 20 & Sombor & 12 & 687 & 150 & 11005 & 162 & 11692 & 172 & 19707 & 334 & 31395 \\
\hline 21 & Subotica & 2 & 434 & 17 & 7237 & 19 & 7671 & 38 & 15400 & 57 & 23071 \\
\hline 22 & Užice & 10 & 525 & 114 & 6542 & 124 & 7067 & 196 & 17990 & 320 & 25057 \\
\hline 23 & Valjevo & 9 & 547 & 119 & 9036 & 128 & 9383 & 201 & 20397 & 329 & 29980 \\
\hline 24 & Vranje & 13 & 400 & 64 & 5240 & 77 & 5640 & 100 & 7980 & 177 & 13620 \\
\hline 25 & Zaječar & 7 & 325 & 79 & 4186 & 86 & 4511 & 108 & 9047 & 194 & 13558 \\
\hline 26 & Zrenjanin & 28 & 586 & 117 & 9087 & 205 & 9673 & 146 & 11202 & 351 & 20875 \\
\hline 27 & Sremska Mitrovica & 16 & 1021 & 189 & 14293 & 205 & 15314 & 418 & 32543 & 632 & 47857 \\
\hline
\end{tabular}

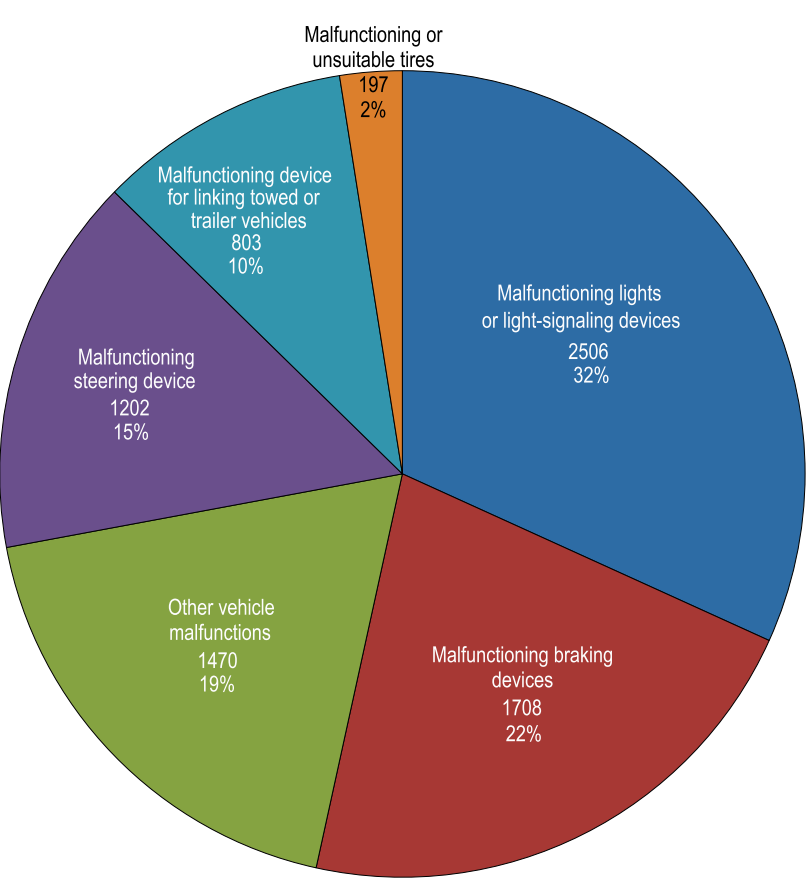

Figure 4 Prevalence of certain causes in the total number of accidents caused by technical malfunction of vehicles in the Republic of Serbia in the 1997-2014 period

Results for the values of correlations between variables are presented in Tab. 3 .

All the values reached in Tab. 3 are positive, which means that with the rise of traffic accidents caused by technical malfunction on vehicles in a particular police district, the total number of traffic accidents rises at the national level as well. This actually represents a logical conclusion.

Table 3 Values of Pearson correlation between variables

\begin{tabular}{|c|c|c|c|c|c|}
\hline $\begin{array}{c}\mathrm{P} \\
\text { Sig. }\end{array}$ & TA FAT* & TA INJ* & $\begin{array}{c}\text { TA } \\
\text { CAS* }\end{array}$ & TA MD* & TA TT* \\
\hline \multirow{2}{*}{ TA FAT } & 0,077 & \multirow{2}{*}{ - } & \multirow{2}{*}{ - } & \multirow{2}{*}{ - } & \multirow{2}{*}{-} \\
\hline & 0,703 & & & & \\
\hline \multirow{2}{*}{ TA INJ } & \multirow[b]{2}{*}{-} & 0,266 & \multirow[b]{2}{*}{-} & \multirow{2}{*}{ - } & \multirow{2}{*}{-} \\
\hline & & 0,180 & & & \\
\hline \multirow{2}{*}{$\begin{array}{c}\text { TA } \\
\text { CAS }\end{array}$} & \multirow{2}{*}{ - } & \multirow{2}{*}{ 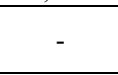 } & 0,238 & \multirow{2}{*}{-} & \multirow{2}{*}{ - } \\
\hline & & & 0,232 & & \\
\hline \multirow{2}{*}{ TA MD } & \multirow[b]{2}{*}{ - } & \multirow[b]{2}{*}{-} & \multirow[b]{2}{*}{-} & 0,364 & \multirow[b]{2}{*}{-} \\
\hline & & & & 0,062 & \\
\hline \multirow{2}{*}{ TA TT } & \multirow{2}{*}{-} & \multirow{2}{*}{-} & \multirow{2}{*}{ - } & \multirow{2}{*}{-} & 0,314 \\
\hline & & & & & 0,110 \\
\hline
\end{tabular}

The aim of the analysis, however, was to establish in what type of traffic accident is the strength of the correlation most evident.

Based on this, in traffic accidents with material damages only (TA MD and TA MD*) the value of the strength is most pronounced and it is $(P=0,364$, sig. 0,062).

The smallest value of the correlation strength is found in traffic accidents with fatalities (TA FAT and TA FAT*) and it is $(P=0,077$, sig. 0,703).

In traffic accidents with injured persons the value of the correlation is $(P=0,266$, sig. 0,180$)$, and in accidents with fatalities the value is $(P=0,238$, sig. 0,232$)$.

All the values achieved in the correlation have reliable amounts of statistical significance (sig.) which essentially demonstrates the reliability of the results achieved between the defined variables. 


\section{CONCLUSIONS}

The working hypotheses set at the beginning of the paper have been found as justified in the following conclusions:

- Results of the study demonstrate that technical malfunctions on vehicles in the Republic of Serbia do not have a great impact on the occurrence of traffic accidents and their consequences.

- The values obtained demonstrate that the whole impact on the occurrence of accidents amounts to $0.72 \%$, which is consistent with the results reached by [3], and inversely not consistent with the conclusions reached by [12] and [14].

- As a cause for the occurrence of accidents with fatalities, technical malfunctions have the greatest value of $1.65 \%$, and the smallest rate is observed in traffic accidents with material damages (only $0.59 \%$ ).

- If we observe the type of technical malfunction as the cause for traffic accidents, it can be concluded that malfunctioning lights or light-signalling devices is the most prevalent one with $32 \%$.

- The least prevalent technical malfunction is observed in malfunctioning or unsuitable tires with the amount of a mere $2 \%$ out of the total number of accidents from that causative group in the Republic of Serbia.

Aside from the analysis at the level of the Republic of Serbia, a comparison on the prevalence of accidents was also carried out at the level of 27 police districts in the Republic of Serbia. By applying the Pearson correlation, a mutual connection of the number of accidents was evaluated according to type at the level of each district, and the total number of accidents at the national level, i.e. the level of the Republic of Serbia. The greatest correlation values were observed in traffic accidents with material damages only, and the smallest values were observed in accidents with fatalities.

The global significance of this research is in abilities to carry out further researches in this field and in possibilities to carry out comparisons with other countries in the region.

The research results also imposed dilemma with regard to a very small percentage of representation of the technical malfunction of vehicles in total number of accidents in the Republic of Serbia and can indicate problems in the existing methodology, which is applied for identification of the key causes of road accidents in this region.

Based on everything stated, it is necessary to conduct in-depth analyses of accidents to establish in more detail to what extent technical malfunctions on vehicles are present in the total number of accidents. Results in this paper are based on the statistical data on traffic accidents in the Republic of Serbia, however, in-depth analyses should be carried out in the coming years for those accidents with the severest consequences, so as to acquire a more realistic representation of the impact of this type of cause on the occurrence of traffic accidents.

In addition, a new by-law is soon to come into effect in the Republic of Serbia, which will regulate the way vehicle inspections are carried out in accordance with the contemporary tendencies laid out in ECE directives that came into effect during the course of 2014.

\section{REFERENCES}

[1] Agarski, B., Kljajin, M., Budak, I., Tadic, B., Vukelic, Dj. Bosak, M., \& Hodolic, J. (2012). Application of multicriteria assessment in evaluation of motor vehicles environmental performances. Tehnički vjesnik, 19(2), 221226

[2] Analiza stanja bezbednosti saobraćaja u Republici Srbiji za period 2001-2012. godine. Agencija za bezbednost saobraćaja Republike Srbije-RTSA, Beograd, 2014.

[3] Cristensen, P. \& Evlik, R. (2007). Effects on accidents of periodic motor vehicle inspection in Norway. Accident Analysis and Prevention, 39, 47-52. https://doi.org/10.1016/j.aap.2006.06.003

[4] Jedinstvena baza podataka od značaja za bezbednost saobraćaja u Republici Srbiji. Agencija za bezbednost saobraćaja Republike Srbije-RTSA, Beograd, 2015.

[5] Palant, Dž. (2014). SPSS Priručnik za preživljavanje, Mikro knjiga, Beograd.

[6] Simić, V. (2013). End-of-life vehicle recycling - A review of the state-of-the-art. Tehnicki vjesnik, 20(2), 371-380.

[7] Stoke, C. B. \& Simpson, C. H. (1982). Truck safety, regulation, inspection and enforcement in Virginia. Annual Meeting of Transportation Research Board, Washington, DC.

[8] Schoor, O. \& Niekerk, J. (2001). Mechanical failures as contributing cause to motor vehicle accidents-South Africa. Accident Analysis and Prevention, 33, 713-721. https://doi.org/10.1016/S0001-4575(00)00083-X

[9] Jones, I. S. \& Stein, H. S. (1989). Defective equipment and tractor-trailer crash involvement in Norway. Accident Analysis and Prevention, 21, 469-481. https://doi.org/10.1016/0001-4575(89)90007-9

[10] Moses, L. N. \& Savage, I. (1992). The effectiveness of motor carrier safety audit. Accident Analysis and Prevention, 24, 479-496. https://doi.org/10.1016/0001-4575(92)90057-P

[11] Elvik, R. (2002). The effect on accidents of technical inspection of heavy vehicles in Norway. Accident Analysis and Prevention, 34, 753-762. https://doi.org/10.1016/S0001-4575(01)00075-6

[12] Fosser, S. (1992). An experimental evaluation of the effects of periodic motor vehicle inspection on accidents rates. Accident Analysis and Prevention, 24, 599-612. https://doi.org/10.1016/0001-4575(92)90012-8

[13] European Commission-ECE, Tougher vehicle testing rules to save lives, 2015. http://ec.europa.eu/transport/road safety/events-archive/2012_07_13_press_release_en.htm. (21.06.2015)

[14] PIARC. (2007). Road accident investigation guidelines for road engineers, Puteaux, France. 


\section{Contact information:}

\section{Đorđe VRANJEŠ, M.Sc.}

Institute of Nuclear Sciences Vinča, Centre for Motors and Vehicles

11351, Vinča, Belgrade, Serbia

djordjevranjes@yahoo.com

Jovica VASILJEVIĆ, PhD, Assistant Professor

Road Traffic Safety Agency of the Republic of Serbia

11070 New Belgrade, Serbia

jovica.vasiljevic@gmail.com

Goran JOVANOV, PhD, Assistant Professor

Academy of Criminalistic and Police Studies of the Republic of Serbia

11080 Belgrade-Zemun, Serbia

goran.jovanov@kpa.edu.rs

Radovan RADOVANOVIĆ, PhD, Full Professor

Academy of Criminalistic and Police Studies of the Republic of Serbia

11080 Belgrade-Zemun, Serbia

radovan.radovanovic@kpa.edu.rs

Tihomir ĐURIĆ, PhD, Assistant Professor

Faculty of Traffic and Transport Engineering Doboj, BiH

74000 Doboj, Bosnia and Herzegovina

tihomir.djuric@stfdoboj.net 